\title{
Catalytic performances of cross-linking humic acids supported Pd/Ni bime- tallic catalyst for heck reaction
}

\author{
Qijie Xut ${ }^{1,2}$, Lei Zhang ${ }^{1,3}$, Wenzhong $\mathrm{Shi}^{2}$, Yuanchen Cui ${ }^{* 1,3}$ \\ ${ }^{1}$ College of Chemistry \& Chemical Engineering, Henan University, Kaifeng 475001, Henan, China; \\ ${ }^{2}$ Department of Chemistry \& Chemical Engineering, Huanghuai University, Zhumadian 463000 Henan, China; \\ ${ }^{3}$ Research Institute of Natural Product and Pharmaceutical Chemistry, Henan University, Kaifeng 475001, Henan, China \\ *Corresponding author: e-mail: yccui@henu.edu.cn
}

\begin{abstract}
The cross-linking humic acids (CL-HAs), epichlorohydrin as the cross-linking reagent and the supported $\mathrm{Pd} / \mathrm{Ni}$ bimetallic catalysts (CL-HAs-Pd/Ni) were prepared and characterized by IR, AAS, XPS, TEM. The effects of reaction time, temperature, base, solvent and the amount of catalyst on the properties of the catalyst were studied. These catalysts could catalyze the Heck reaction of aryl halides and substituted aryl halides with acrylic acids or styrene successfully; the yields were all above $95 \%$.
\end{abstract}

Keywords: cross-linking humic acid; epichlorohydrin; Pd/Ni bimetallic catalyst; supported catalyst; Heck reaction.

\section{INTRODUCTION}

The Heck reaction of aryl halide with vinyl compounds has been widely applied in agrochemistry ${ }^{1}$, fine chemis$\operatorname{try}^{2}$, chemical intermediate ${ }^{3}$ etc, and has gradually become an important means in organic synthesis gradually. The homogeneous catalysts were presented by the complexes of phosphorus-palladium in early catalysts of Heck reaction. However, the disadvantages of this kind of catalysts such as instability at high temperature or pollution to the environment, greatly restricted their application of the catalyst in industry. Polymer supported metal catalysts have developed greatly, which can overcome the disadvantages of the homogeneous catalysts. Polymer supported metal catalysts demonstrate high activity and selectivity for the Heck reaction, and can be reused many times. The disadvantages of the synthetic polymers used for catalyst carriers are their high cost and pollution to the environment, and that is not suitable for the application in the field of environmental protection. Fortunately, natural polymers supported metal catalysts have been developed; they are friendly to the environment, biodegradable, and cheaper, and they have gained great attention due to their application prospect. A few papers reported on the application of the natural polymer supported palladium catalysts in the Heck reaction, such as chitosan ${ }^{4}$, sesbania gum $^{5}$, starch $^{6,7}$, phthalocyanine ${ }^{8}$, cellulose ${ }^{9}$ etc. But most of these catalysts can only catalyze the Heck reaction between iodobenzene and vinyl compounds; few catalysts could catalyze the Heck reaction between bromobenzene and vinyl compounds.

Humic acids (HA), as natural organic macromolecules, arise from the decay of plant and animal residues mainly through biochemistry and geochemistry, and widely exist in peat, lignite, stream, river, wetland, lake, and ground waters. Humic acids, which contain 50\% 90\% in total organic compounds, $70 \% \sim 80 \%$ in soil, $40 \% \sim 60 \%$ in organic carbon dissolved in water, are the main organic carbon on the surface of the earth. The structures of humic acids contain a carboxyl group (-COOH), a hydroxyl group $(-\mathrm{OH})$, an amino group (- $\left.\mathrm{NH}_{2}\right)$, a quinonyl group $\left(-\mathrm{C}_{6} \mathrm{H}_{3} \mathrm{O}_{2}\right)$, all of which can form functional humic acids by chemical methods. However, humic acids and func- tional humic acids were mainly used in agriculture, forestry, biopharmaceutical, petroleum additive industry and so on in the past few years, only a few reports on HA were applying in catalyzing organic reaction ${ }^{\mathbf{1 0}, 11}$. In this work, CL-HAs were synthesized by using epichlorohydrin as cross-linking reagent. The Heck reactions of aryl halide with vinyl compounds were studied by using cross-linking humic acid supported $\mathrm{Pd} / \mathrm{Ni}$ bimetal catalysts. The effects of different conditions on catalytic properties were researched by using the Heck reaction of bromobenzene with acrylic acid. The recyclability of the catalyst and the effect of different reagents on the catalytic properties of catalyst were also investigated.

\section{EXPERIMENTAL}

\section{Equipments and reagents}

The IR spectra were performed on an Avatar 360 Fourier transform infrared (FT-IR) spectrometer (Nicolet Co., USA). The atomic absorption spectroscopy (AAS) was performed on an AA-6601F spectrophotometer (Hitachi Co., Japan). The thermal analysis was performed on an EXSTAR6000 (Seiko Co., Japan) thermal analysis system at a heating rate of $10{ }^{\circ} \mathrm{C} / \mathrm{min}$ in $\mathrm{N}_{2}$ atmosphere.

Humic acids, $\mathrm{PdCl}_{2}$, acrylic acid, styrene, dimethylformamide (DMF), N-methyl-2-pyrrolidone (NMP), 4-iodobenzene(98\%), 4-bromobenzene(98\%), 4chlorobenzene(98\%), 1-iodo-4-nitrobenzene(98\%), 1bromo-4-nitrobenzene (98\%), 1-chloro-4-nitrobenzene( $98 \%$ ), 4-iodotoluene (98\%), 4-bromotoluene, $m$ bromo-benzoic acid, $m$-iodo-benzoic acid, 4-methoxyiodobenzene, tetrabutyl ammonium bromides (TBABr) and other reagents were obtained from commercial sources and used as received.

\section{Synthesis of cross-linking humic acids with epichlorohydrin}

Humic acids, epichlorohydrin were placed in a $100 \mathrm{~mL}$ three neck flask, then $10 \mathrm{~mL} 5 \% \mathrm{NaOH}$ solution was added in the mixture. The mixture was stirred at room temperature for $18 \mathrm{~h}$, filtered and washed with distilled water, ethanol, diethyl ether, and dried $50^{\circ} \mathrm{C}$ in a vacuum 


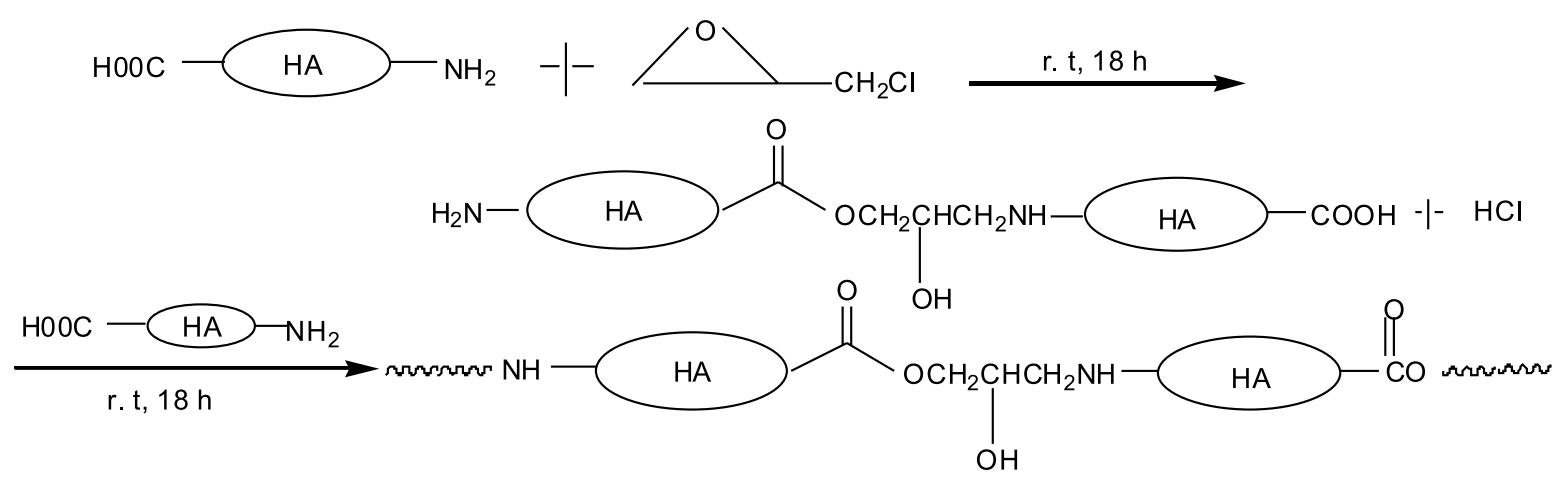

Figure 1. The reaction equation of the cross-linking humic acids with epichlorohydrin

oven for $24 \mathrm{~h}$. The product was characterized by the IR spectrum. The dissolvability properties of HA and CL$\mathrm{HA}$ in water and $3 \% \mathrm{NaOH}$ solution were investigated respectively. The result revealed that they showed great difference in dissolvability. Humic acid could dissolve in water and $3 \% \mathrm{NaOH}$ solution easily, but cross-linking humic acid was hard to dissolve. It indicated that CL-HA was more stable in the solvent than the humic acid. The sketch of the cross-linking reaction of humic acid was shown in fig.1.

\section{Synthesis of the cross-linking humic acids supported palladium and nickel complex}

The cross-linking humic acids and distilled water were placed in $100 \mathrm{~mL}$ three neck flask. After stirring for 10 min, palladium chloride was added to the mixture solution, and the mixture was stirred $85^{\circ} \mathrm{C}$ for $72 \mathrm{~h}$. Nickel chloride was added to the mixture solution, and the mixture was stirred at the same temperature for $72 \mathrm{~h}$ continually. The mixture solution was filtered and washed with plenty of distilled water, and dried at $50^{\circ} \mathrm{C}$ in the vacuum oven for $24 \mathrm{~h}$. The amounts of palladium and nickel in the complex were $1.45 \mathrm{mmol} \cdot \mathrm{g}^{-1}$ and $2.82 \mathrm{mmol} \cdot \mathrm{g}^{-1}$ by AAS analysis respectively.

\section{The catalytic properties of $\mathrm{CL}-\mathrm{HA}-\mathrm{Pd} / \mathrm{Ni}$ bimetallic cata-} lyst

CL-HA-Pd complex (0.038 mmol), acrylic acid (6.0 $\mathrm{mmol})$, aryl halide $(5 \mathrm{mmol})$, tributylamine $(6.0 \mathrm{mmol})$ and $\mathrm{TBABr}$ were taken in a three neck flask and stirred in $\mathrm{N}_{2}$ atmosphere for $12 \mathrm{~h}$. After the reaction mixture was cooled to room temperature, $\mathrm{H}_{2} \mathrm{O}(25 \mathrm{~mL})$ and $\mathrm{Na}_{2} \mathrm{CO}_{3}$ $(1.0 \mathrm{~g})$ were added. After being stirred for $10 \mathrm{~min}, \mathrm{CL}-$ HA-Pd complex was separated by filtration. The filtrate was treated with $3 \mathrm{~N} \mathrm{HCl}(5 \mathrm{~mL})$. The precipitate was filtered, washed with $\mathrm{H}_{2} \mathrm{O}(2 \times 15 \mathrm{~mL})$ and dried in the air to give trans-cinnamic acid. $15 \mathrm{~mL}$ ether was added in the reaction flask when the Heck reaction of bromobenzene with styrene was ended and cooled, and then the mixture solution was filtrated, concentrated, washed, dried, and weighed.

\section{RESULTS AND DISCUSSION}

\section{Characterization}

Table 1 showed the XPS data of $\mathrm{NiCl}_{2}, \mathrm{Pd}, \mathrm{PdCl}_{2}, \mathrm{Cl}-$ $\mathrm{HA}, \mathrm{Cl}-\mathrm{HA}-\mathrm{Pd} / \mathrm{Ni}$. The binding energy of $\mathrm{O}_{1 \mathrm{~s}}$ in CL-HA$\mathrm{Pd} / \mathrm{Ni}$ catalyst was higher than that in CL-HA. The reason may be that the coordination bond of $\mathrm{O}$ and $\mathrm{Pd} / \mathrm{Ni}$ makes the binding energy of $\mathrm{O}_{1 \mathrm{~s}}$ increase $\left(\mathrm{O} \rightarrow \mathrm{Pd}^{2+} / \mathrm{Ni}^{2+}\right)$. The increase of the binding energy of N1s accounts for the transferring lone electron pair of $\mathrm{N}_{1 \mathrm{~s}}$ to $\mathrm{Pd} / \mathrm{Ni}\left(\mathrm{N} \rightarrow \mathrm{Pd}^{2+}\right.$ / $\mathrm{Ni}^{2+}$ ), which leads to the decreasing of the density of electron around $\mathrm{N}^{[4]}$. The binding energy of $\mathrm{Pd}$ (II), $\mathrm{Pd}$ (0) and Ni (II) in CL-HA-Pd/Ni was $338.0 \mathrm{eV}, 336.0 \mathrm{eV}$ and $856.3 \mathrm{eV}$ respectively.

Various functional groups exist in the molecular structure of HA; these functional groups can be modified by a chemical method. The amine group and the carboxylic group of HA can interact with a chlorine atom and epoxy group of epoxy chloropropane molecule, respectively. The structure of CL-HA is formed. Such CL-HA shows better stability in acid solution or base solution.

The IR spectra of HA (b) and CL-HA (a) are shown in Fig.2. The main features of these spectra and their corresponding assignments, according to Bellanmy ${ }^{\mathbf{1 2}}$, Mac Carthy and Rice ${ }^{\mathbf{1 3}}$, Stevenson ${ }^{\mathbf{1 4}}$ and Fan Kangnian ${ }^{\mathbf{1 5}}$, are the following: the peak of methylene in $2914 \mathrm{~cm}^{-1}$, this may be absorption peak of methylene of epichlorohydrin after cross-linking reaction of humic acids with epichlorohydrin. There are characteristic peaks of ester: $1733 \mathrm{~cm}^{-1}(\mathrm{C}=\mathrm{O}), 1055 \mathrm{~cm}^{-1}, 1106 \mathrm{~cm}^{-1}, 1168 \mathrm{~cm}^{-1}$ (stretching vibration of $\mathrm{C}-\mathrm{O}$ ). The contrast of CL-HA and HA shows that $3400 \mathrm{~cm}^{-1}$ absorption peak in CL-HA is narrower than that in HA. The reason may be that symmetric and anti-symmetric stretching of the primary amine of humic acid turns to the stretching vibration of the secondary amine of the cross-linking humic acid. And the structure of the cross-linking humic acid was steadier than that of humic acid, which was better for the carrier. The amido of humic acid can interact with palladium and nickel to form a steady complex, which was used for catalytic reaction.

Table 1. XPS data for $\mathrm{NiCl}_{2}, \mathrm{Pd}, \mathrm{PdCl}_{2}, \mathrm{Cl}-\mathrm{HA}, \mathrm{Cl}-\mathrm{HA}-\mathrm{Pd} / \mathrm{Ni}\left(\mathrm{eV}^{*}\right)$

\begin{tabular}{|l|c|c|c|c|}
\hline Samples & $\mathrm{Pd}_{3 \mathrm{~d} 5 / 2}$ & $\mathrm{Ni}_{2 \mathrm{p}}$ & $\mathrm{O}_{1 \mathrm{~s}}$ & $\mathrm{~N}_{1 \mathrm{~s}}$ \\
\hline $\mathrm{NiCl}_{2}$ & & 855.6 & & \\
\hline $\mathrm{Pd}$ & 335.3 & & & \\
\hline $\mathrm{PdCl}{ }_{2}$ & 338.3 & & $531.9,535.6$ & 399.5 \\
\hline $\mathrm{CL}-\mathrm{HA}$ & & & $532.2,535.9$ & 402.0 \\
\hline $\mathrm{CL}-\mathrm{HA}-\mathrm{Pd} / \mathrm{Ni}$ & $336.0,338.0$ & 856.3 & & \\
\hline
\end{tabular}




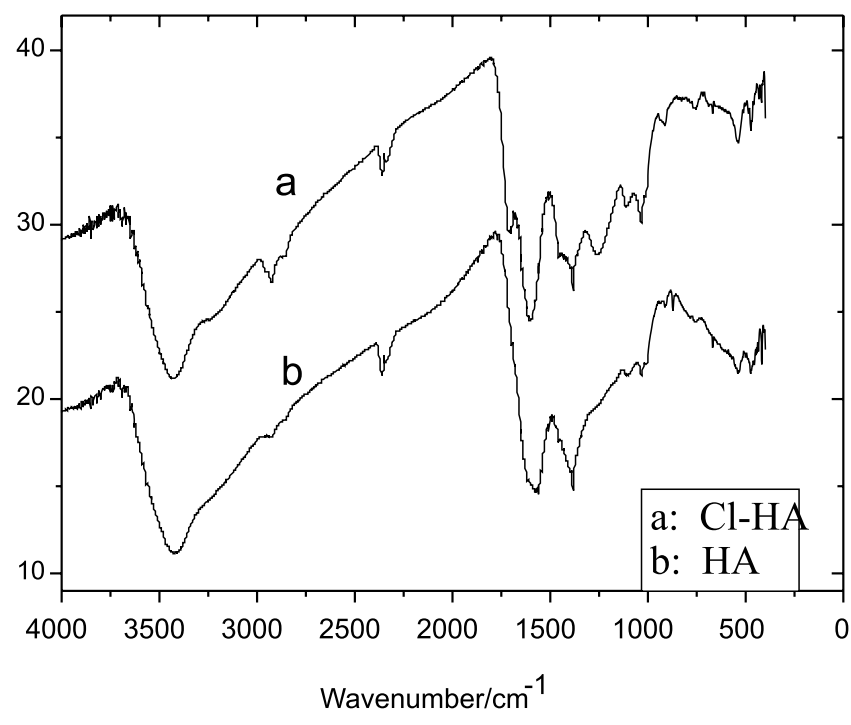

Figure 2. FTIR spectroscopy of HA and CL-HA

\section{The studies on the catalytic properties of the catalyst}

The effects of the base and solvent on the catalytic properties were studied by using the Heck reaction of bromobenzene with acrylic acid under $\mathrm{N}_{2}$ atmosphere. The results were shown in Table 2 . Base is important in the reaction process, because it can bind up $\mathrm{HBr}$ produced in the reaction process, which can facilitate this reaction. $\mathrm{Bu}_{3} \mathrm{~N}$ was not only acid acceptor, but was concerned with the regeneration of CL-HA-Pd/Ni catalyst by the reduction elimination reaction of $\mathrm{HBr}$, which was in favor of the recyclability of the catalyst. The yield was $100 \%$ by using $\mathrm{Bu}_{3} \mathrm{~N}$ as base at $120^{\circ}$ in the presence of $\mathrm{TBABr}$ as the solvent for $12 \mathrm{~h}$. Other bases such as $\mathrm{Na}_{2} \mathrm{CO}_{3}, \mathrm{NaHCO}_{3}, \mathrm{Et}_{3} \mathrm{~N}$ or no alkali were not as effective as $\mathrm{Bu}_{3} \mathrm{~N}$, only afforded moderate to low yields of the coupling products. There was an interesting phenomenon that this catalyst can catalyze the Heck reaction of bromobenzene without the base. We think that there is an equilibrium between $\mathrm{TBABr}$ and $\mathrm{Bu}_{3} \mathrm{~N}$, $\left[\mathrm{Bu}_{4} \mathrm{~N}\right] \mathrm{Br} \rightarrow \mathrm{Bu}_{3} \mathrm{~N}+\mathrm{BuBr}$, so that the yield of the product is $29 \%$ in the condition without the base. In addition, the effect of the amount of $\mathrm{Bu}_{3} \mathrm{~N}$ on the catalytic property was also studied and the results were shown in Fig. 3. The yield was gradually increased as the amount of the base was increased. When the amount of the base was above $0.6 \mathrm{~mL}$, the yield was $100 \%$ at $120^{\circ} \mathrm{C}$ in the presence of $\mathrm{TBABr}$ as the solvent for $12 \mathrm{~h}$.

The solvent was very important in the reaction process, because it can protect the catalytic activity of the catalyst. TBABr was a better solvent than other solvents such as NMP, DMF, $\mathrm{Bu}_{4} \mathrm{I}$ and no solvent. The yield was $100 \%$ at $120^{\circ}$ in the presence of $\mathrm{Bu}_{3} \mathrm{~N}$ as the base for $12 \mathrm{~h}$ under $\mathrm{N}_{2}$ atmosphere. The yield was very low at the same condition in the presence of another base. We think that $\mathrm{TBABr}$ has the character of ion liquid as a reaction medium, and that is beneficial for the reaction system ${ }^{\mathbf{1 7}}$; TBABr can form $\left[\mathrm{Bu}_{4} \mathrm{~N}\right]_{2}\left[\mathrm{PdX} \mathrm{X}_{3} \mathrm{Ph}\right]$ structure with metal

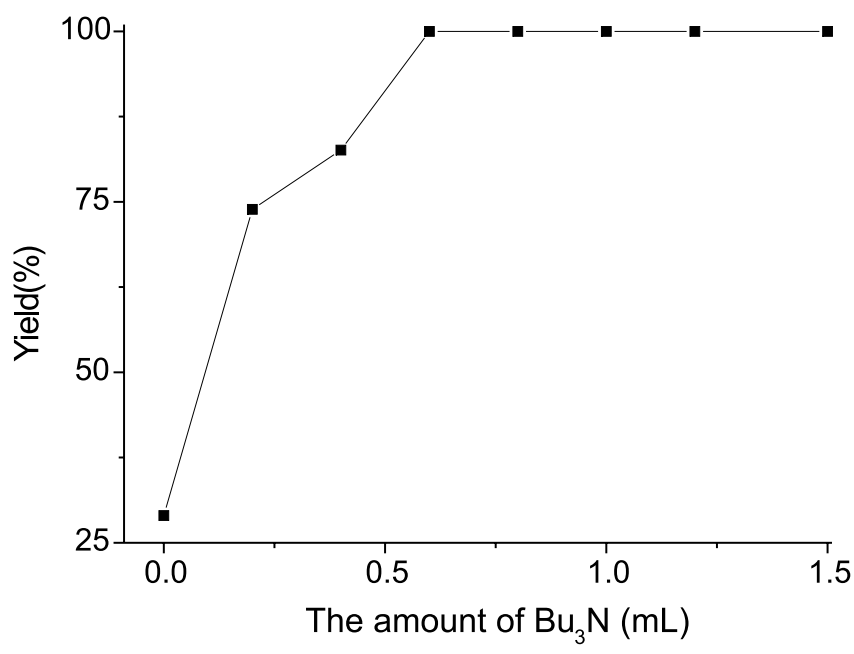

Figure 3. The effect of amount of $\mathrm{Bu}_{3} \mathrm{~N}$ on catalytic properties

ion, which can prevent the palladium black formed from $\operatorname{Pd}(0)$, and increase the catalytic activity of the catalyst ${ }^{\mathbf{1 5}}$. The yields were very high in $\mathrm{N}_{2}$ atmosphere by using the Heck reaction of bromobenzene and acrylic acid, but the yield was $34.8 \%$ in air atmosphere in the same condition, because $\mathrm{O}_{2}$ in air can oxidize $\operatorname{Pd}(0)$ to $\operatorname{Pd}(\mathrm{II})$, which is bad to the catalytic reaction. In all, the condition of $\mathrm{N}_{2}$ atmosphere, $\mathrm{TBABr}$ and $\mathrm{Bu}_{3} \mathrm{~N}$ was the best reaction system.

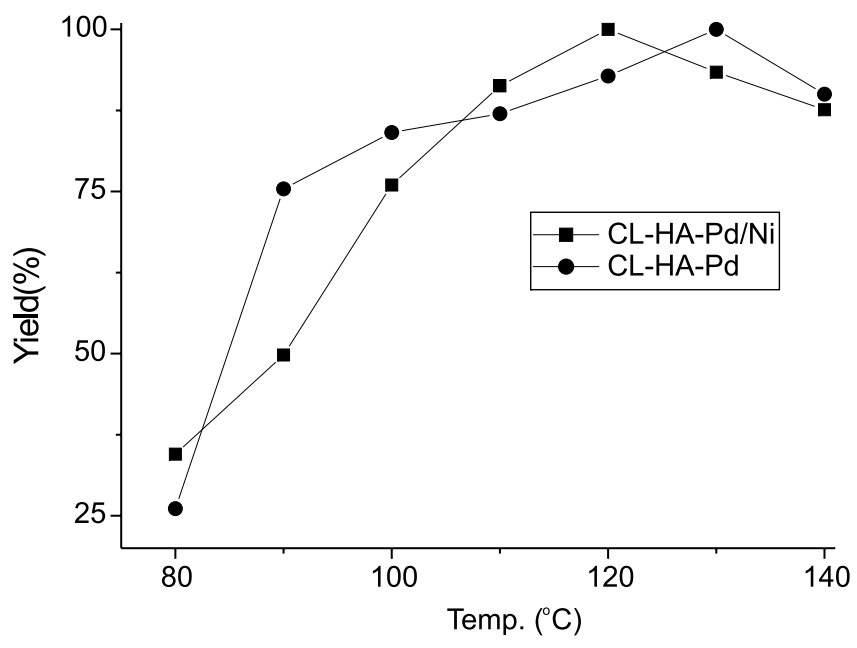

Figure 4. The effect of temperature on the catalytic properties

The effects of temperature and reaction time on the Heck reaction were very important. Many researchers found that the Heck reaction of iodobenzene and vinyl compounds can easily proceed with low temperature $\left(80^{\circ} \mathrm{C}\right)$ and short time $(0.5 \mathrm{~h})^{\mathbf{8 , 1 8 - 2 0}}$. The Heck reaction of bromobenzene and vinyl compounds requires higher temperature (more than $140^{\circ} \mathrm{C}$ ) and longer reaction time (more than $14 \mathrm{~h}$ ) while the yields were still very low ${ }^{21-22}$.

The effects of temperature and reaction time on the catalytic properties of the catalyst were studied by using

Table 2. The effect of the base and the solvent on the catalytic properties ${ }^{\mathrm{a}}$

\begin{tabular}{|c|c|c|c|c|c|c|c|c|c|c|}
\hline Base & ------- & $\mathrm{NaHCO}_{3}$ & $\mathrm{Na}_{2} \mathrm{CO}_{3}$ & $\mathrm{Et}_{3} \mathrm{~N}$ & $\mathrm{Bu}_{3} \mathrm{~N}$ & $\mathrm{Bu}_{3} \mathrm{~N}$ & $\mathrm{Bu}_{3} \mathrm{~N}$ & $\mathrm{Bu}_{3} \mathrm{~N}$ & $\mathrm{Bu}_{3} \mathrm{~N}$ & $\mathrm{Bu}_{3} \mathrm{~N}^{\mathrm{b}}$ \\
\hline Solvent & $\mathrm{TBABr}$ & $\mathrm{TBABr}$ & $\mathrm{TBABr}$ & $\mathrm{TBABr}$ & $\mathrm{TBABr}$ & $\mathrm{NMP}$ & $\mathrm{DMF}$ & $\mathrm{Bu}_{4} \mathrm{I}$ & ----- & $\mathrm{TBABr}$ \\
\hline Yield (\%) & 29.0 & 72.5 & 84.1 & 91.7 & 100 & 11.6 & 14.5 & 20.3 & 31.9 & 34.8 \\
\hline
\end{tabular}

Reaction condition: bromobenzene $5 \mathrm{mmol}$, acrylic acid $10 \mathrm{mmol}$, TBABr $0.8 \mathrm{~g}$, time $12 \mathrm{~h}$, temperature 120 ?, the amount of the catalyst $0.02 \mathrm{~g} ;{ }^{a}$ the reaction occurred in $\mathrm{N}_{2}$ atmosphere, ${ }^{\mathrm{b}}$ the reaction occurred in the air atmosphere 


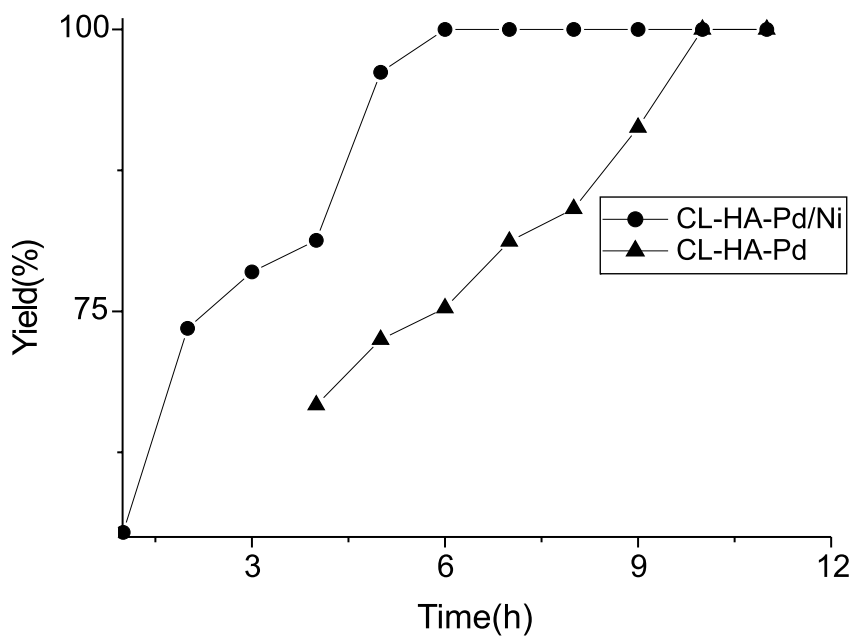

Figure 5. The effect of reaction time on the catalytic properties

the Heck reaction of bromobenzene and acrylic acid in the presence of TBABr as the solvent, $\mathrm{Bu}_{3} \mathrm{~N}$ as the base, supported $\mathrm{Pd} / \mathrm{Ni}$ bimetal complex or supported $\mathrm{Pd}$ complex as catalyst at $120^{\circ} \mathrm{C}$ for $12 \mathrm{~h}$, and the ratio of bromobenzene and palladium was 200: 1. The results were shown in Fig.4 and Fig.5.

The CL-HA supported $\mathrm{Pd} / \mathrm{Ni}$ bimetal catalyst can catalyze the Heck reaction of bromobenzene and acrylic acid at low temperature $\left(80^{\circ} \mathrm{C}\right)$, the yield was $100 \%$ at $110^{\circ} \mathrm{C}$. And the catalyst can catalyze the Heck reaction of bromobenzene and acrylic acid at $120^{\circ} \mathrm{C}$ in the presence of $\mathrm{TBABr}$ as the solvent and $\mathrm{Bu}_{3} \mathrm{~N}$ as the base for $1 \mathrm{~h}$, the reaction can be almost completed in $5 \mathrm{~h}$. Compared with the Heck reaction of bromobenzene and acrylic acid catalyzed by CL-HA-Pd and CL-HA-Pd/Ni, they can catalyze the Heck reaction in short time, but the rate of the reaction catalyzed by CL-HA-Pd/Ni was higher than that by CL-HA-Pd in Fig.4 and Fig.5. The differences of the two catalysts may be that the synergistic effect of $\mathrm{Pd}$ and $\mathrm{Ni}$ in the bimetal catalyst can increase the reaction rate, and the results are consistent with that papers reported $^{11,23-24}$.

Table 3 showed that the yield increases with the increase of the ratio of the catalyst and bromobenzene. The product yield was $100 \%$ when the ratio of bromobenzene and palladium was 250: 1, but the product yield decreased with the increment of palladium content. This result was in accordance with that reported by Iweta $\mathrm{P}^{\mathbf{1 6}}$. The reason may be that the Pd (0) dissolved in the solvent increased with the increasement of the amount of the catalyst, and $\mathrm{Pd}(0)$ aggradation also increased, which made the catalyst lose its activity.

The recyclability of the CL-HA-Pd/Ni catalyst was studied by using the Heck reaction of bromobenzene and acrylic acid. The solvent, base and reagents were invariable in the process of the catalyst reused. The results were shown in Table 4. The catalyst can catalyze the Heck reaction after reusing 4 times. The results of AAS showed

Table 3. The effect of the catalyst amount on the catalytic properties

\begin{tabular}{|c|c|c|c|c|}
\hline $\begin{array}{c}\text { Bromobenzene/ } \\
\text { Pd (mol/mol) }\end{array}$ & $400: 1$ & $250: 1$ & $200: 1$ & $150: 1$ \\
\hline Yield (\%) & 75.4 & 100 & 100 & 82.0 \\
\hline
\end{tabular}

The reaction condition: bromobenzene $5 \mathrm{mmol}$, acrylic acid $10 \mathrm{mmol}$, time $12 \mathrm{~h}$, base $\mathrm{Bu}_{3} \mathrm{~N} 1 \mathrm{~mL}$, solvent TBABr $0.9 \mathrm{~g}$ that the palladium and nickel content were 1.45 mmol.g ${ }^{-1}$ and $2.82 \mathrm{mmol.g}^{-1}$ respectively. Palladium and nickel were not detected in the solution after reaction, which accounted for that metal ion was not lost in reaction solution, and the catalysts were steady. But the results of TEM showed that metal aggradation was found after reaction, which was the primary reason that the catalyst activity was reduced in the reaction process.

Table 4. The recyclability of CL-HA-Pd/Ni catalyst

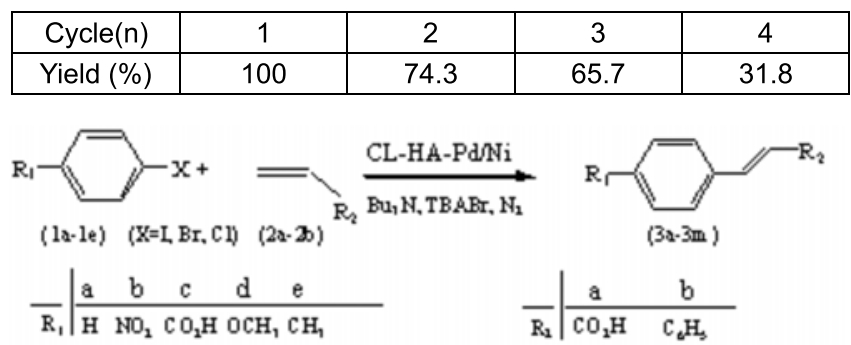

Figure 6. The equation of Heck reaction

We examined the Heck reaction of a variety of aryl halides with acrylic acid or styrene, as figure 6 , at $120^{\circ} \mathrm{C}$ in the presence of $0.8 \mathrm{~g} \mathrm{TBABr}$ as the solvent, $1 \mathrm{~mL} \mathrm{Bu}_{3} \mathrm{~N}$ as base and $0.02 \mathrm{~g}$ catalyst for $12 \mathrm{~h}$. The results were shown in table 5. The CL-HA-Pd/Ni catalyst not only catalyzes the Heck reaction of iodobenzene, bromobenzene, substituted iodobenzene, substituted bromobenzene and acrylic acids or styrene, but also can catalyze the Heck reaction of chlorobenzene, substituted chlorobenzene with acrylic acid or styrene.

Table 5. The effect of different reagents on the catalytic properties

\begin{tabular}{|c|c|c|c|c|c|}
\hline Entry & $\mathrm{R}_{1}$ & $\mathrm{X}$ & $\mathrm{R}_{2}$ & Products & $\begin{array}{c}\text { Yield } \\
(\%)\end{array}$ \\
\hline 1 & $1 \mathrm{a}$ & $\mathrm{I}$ & $2 \mathrm{a}$ & $3 \mathrm{a}$ & 100 \\
\hline 2 & $1 \mathrm{~b}$ & $\mathrm{I}$ & $2 \mathrm{a}$ & $3 \mathrm{~b}$ & 100 \\
\hline 3 & $1 \mathrm{c}$ & $\mathrm{I}$ & $2 \mathrm{a}$ & $3 \mathrm{c}$ & 100 \\
\hline 4 & $1 \mathrm{~d}$ & $\mathrm{I}$ & $2 \mathrm{a}$ & $3 \mathrm{~d}$ & 100 \\
\hline 5 & $1 \mathrm{e}$ & $\mathrm{I}$ & $2 \mathrm{a}$ & $3 \mathrm{e}$ & 100 \\
\hline 6 & $1 \mathrm{a}$ & $\mathrm{Br}$ & $2 \mathrm{a}$ & $3 \mathrm{f}$ & 100 \\
\hline 7 & $1 \mathrm{a}$ & $\mathrm{Br}$ & $2 \mathrm{~b}$ & $3 \mathrm{~g}$ & 100 \\
\hline 8 & $1 \mathrm{~b}$ & $\mathrm{Br}$ & $2 \mathrm{a}$ & $3 \mathrm{~h}$ & 100 \\
\hline 9 & $1 \mathrm{c}$ & $\mathrm{Br}$ & $2 \mathrm{a}$ & $3 \mathrm{i}$ & 100 \\
\hline 10 & $1 \mathrm{e}$ & $\mathrm{Br}$ & $2 \mathrm{a}$ & $3 \mathrm{j}$ & 96.0 \\
\hline 11 & $1 \mathrm{a}$ & $\mathrm{Cl}$ & $2 \mathrm{a}$ & $3 \mathrm{k}$ & 28.9 \\
\hline 12 & $1 \mathrm{a}$ & $\mathrm{Cl}$ & $2 \mathrm{~b}$ & $3 \mathrm{l}$ & 30.2 \\
\hline 13 & $1 \mathrm{~b}$ & $\mathrm{Cl}$ & $2 \mathrm{a}$ & $3 \mathrm{~m}$ & 36.2 \\
\hline
\end{tabular}

\section{CONCLUSION}

In summary, we synthesized the CL-HA-Pd/Ni catalysts, and the catalysts exhibit high catalytic activity by using the Heck reaction of aryl halide with vinyl compounds in the $\mathrm{N}_{2}$ atmosphere. The catalysts can be reused for several times. The catalysts can also catalyze the Heck reaction of the substituted aryl halide with vinyl compounds.

\section{Acknowledgments}

This work was supported by the Natural Science Foundation of Henan Province in China (Project1 No.0611020500 and Project 2 No:092300410121). 


\section{LITERATURE CITED}

1. Biffis, A., Zecca, M. \& Basato, M.(2001).Palladium metal catalysts in Heck C--C coupling reactions. J mol Catal A Chem, 173(1-2): 249-274.DOI:10.1016/S1381-1169(01)00153-4.

2. Deiters, A. \& Stephen, F. M.(2004). Synthesis of Oxygen- and Nitrogen-Containing Heterocycles by Ring-Closing Metathesis. Chem. Rev., 104 (5):2199-2238.10.1021/cr0200872.

3. Irina, P. \& Andrei, V.(2000). The Heck Reaction as a Sharpening Stone of Palladium Catalysis. Chem Rev, 100(8): 3009-3066.DOI:10.1021/cr9903048.

4. Liu, P., Wang, L. \& Li, L. M. et al.(2004). Study on the Heck Arylation Reaction Catalyzed by Chitosan-Immobilized Palladium(0) Complex. Chin J Orgc Chem, 24(1): 59-65. DOI: CNKI:SUN:YJHU.0.2004-01-010.

5. Liu, D. G., Lee, J. F. \& Tang, M. T.(2005). Characterization of $\mathrm{Pt}-\mathrm{Ru} / \mathrm{C}$ catalysts by $\mathrm{X}$-ray absorption spectroscopy and temperature-programmed surface reaction. J Mol Catal A Chem, 231(1-2): 197-206. DOI: 10.1016/ j.molcata.2005.07.011.

6. Zhang, H. F., Zhang, L. \& Cui, Y. Ch.(2007). Synthesis of chitosan microsphere-resin supported palladium complex and its catalytic properties for Mizoroki-Heck reaction. React. Funct. Polym., 67(4): 322-328. DOI: 10.1016/j. reactfunctpolym.2007.01.004.

7. Zhang, L. \& Cui, Y C.(2005). Synthesis of Starch Supported Palladium Catalyst and Its Catalytic Properties for Heck Reaction. Chin J Appl CHem, 22(4): 440-445. DOI: CNKI:SUN:YYHX.0.2005-04-00J.

8. Sun, Q., Zhang, Zh. Q. \&, Su, Y. Ch. et al.(1994). The Best Catalytic Condition of Multi-Nuclear Pd(?)-Ni(?) Phthalocyanine for Heck Reaction Selected with Orthogonal Test. J. Northeast Normal University, 2(2): 53-56. DOI: CNKI:SUN:DBSZ.0.1994-02-013.

9. Reddy, R. K., Kumar, N. S. \& Surendra, P. R. et al.(2006).Cellulose supported palladium(0) catalyst for Heck and Sonogashira coupling reactions. J Mol. Catal. A. Chem., 252(1-2): 12-16. DOI: 10.1016/j.molcata. 2006.02.024.

10. Klavins, M. J. \& Dipane, K. B.(2001). Influence of colloid suspensions of humic acids upon the alkaline fading of carbocations. Chemosphere, 21(7-8): 555-560. DOI: 10.1002/ poc. 1317 .

11. Klavins, M. J. \& Babre, K.(2002). Decarboxylation and alkaline colour fading reactions in presence of humic substances. Chemosphere, 49(6): 685-689. DOI: 10.1016/S00456535(02)00303-X.

12. Bellamy, L. J., The infrared spectra of complex molecules[M]. Chapman and Hall, London, 1975.

13. Stevenson, F. J. Humus chemistry: genesis, composition, reactions [M]. Wiley-interscience, New York, 1994.

14. Fan, K. N. An introduction of spectroscopy[M]. Higher education press, Bei Jing, 2001.

15. Fujita, S., Yoshida, T. \& Bhanage, B. M. et al.(2002). Heck reaction with a silica-supported Pd-TPPTS liquid phase catalyst: effects of reaction conditions and various amines on the reaction rate. $J$ Mol Catal A Chem, 188(1-2): 37-43. DOI: 10.1016/S1381-1169(02)00336-9.

16. Iweta, P. R., Anna, M. T. \& Jozef, J. Z.(2006). Basefree efficient palladium catalyst of Heck reaction in molten tetrabutylammonium bromide. J Mol Catal A Chem, 257, 38. DOI: 10.1016/j.molcata.2006.03.064.

17. Li, R. X. Green solvent (the synthesis and application of ion liquid) [M]. Chemical industry press, 2004.

18. Zhang, L. \& Cui, Y. C.(2005). Synthesis of Polyvinyl Chloride-triethylene-tetramine Supported Pal- ladium Complex and Its Catalytic Properties for Heck Reaction. Acta Chimica Sinica, 10: 924-930. DOI: CNKI:SUN:HXXB.0.200510-009.

19. Jiang, J. Z. \& Cai, C.(2006). In situ formation of dispersed palladium nanoparticles in microemulsion: Effi- cient reaction system for ligand-free Heck reaction. $J$ Collid Interf Sci, 2006, 299(2): 938-943. DOI: 10.1016/ j.jcis.2006.02.035.

20. Perez, R., Veronese, D. \& Coelho, F.(2006). Palladium catalyzed Heck reaction of arenediazonium tetrafluoroborate salts with Baylis-Hillman adducts: production of $\alpha$-benzyl- $\beta$ keto esters. Tetrahedron Lett, 47(8): 1325-1328. DOI: 10.1016/ j.tetlet.2005.12.058.

21. Chen, F. X., Kelvin, T. \& Shen, Sh. C. et al.(2007). Porous magnesia as solid base for ligand-free Heck reaction. Catal Commun, 8(3): 405-409. DOI: 10.1016/ j.catcom.2006.06.032.

22. Cai, M. Zh., Xu, Q. H. \& Jiang, J. W.(2006). The first MCM-41-supported thioether palladium(0) complex: A highly active and stereoselective catalyst for Heck arylation of olefins with aryl halides. J Mol Catal A Chem, 260(1-2): 190-196. DOI: $10.1016 /$ j.molcata.2006.07.014.

23. Sun, Q., Yao, X. H., Su, Y. Ch. et al.(1994). Catalytic Study on Heck Reaction by Multi-nuclear Pd(?) Ni(?)(1:1) Phthalocyanine. J Synthetic Chem, 2(3), 282-286. DOI: CNKI:SUN:HCHX.0.1994-03-015.

24. Reetz, M. T., Breinbauer, R., Wanninger, K.(1996). Suzuki and Heck reactions catalyzed by preformed palladium clusters and palladium/nickel bimetallic clusters. Tetrahedron Lett, 37(26): 4499-4502. DOI: 10.1016/00404039(96)00924-0. 